Research Article

\title{
Investigation of the Sedimentation Property of Backfill Material on the Basis of Rheological Test: A Case Study of Iron Tailings
}

\author{
Yong Wang $\mathbb{C}^{1},{ }^{1,2}$ Aixiang Wu $\mathbb{D}^{1},{ }^{1}$ Lianfu Zhang, ${ }^{1}$ Hongjiang Wang, ${ }^{1}$ and Fei Jin ${ }^{1}$ \\ ${ }^{1}$ School of Civil and Resource Engineering, University of Science and Technology Beijing, Beijing 100083, China \\ ${ }^{2}$ State Key Laboratory of Coal Resources and Safe Mining, China University of Mining and Technology, Xuzhou 221116, China
}

Correspondence should be addressed to Yong Wang; wangyong8551@126.com and Aixiang Wu; wuaixiang@ces.ustb.edu.cn

Received 18 March 2018; Revised 24 May 2018; Accepted 8 July 2018; Published 1 August 2018

Academic Editor: Ana Moldes

Copyright (c) 2018 Yong Wang et al. This is an open access article distributed under the Creative Commons Attribution License, which permits unrestricted use, distribution, and reproduction in any medium, provided the original work is properly cited.

\begin{abstract}
Sedimentation of filling materials could cause pipe blocking accident in mines. However, few quantitative characterization studies have investigated the sedimentation characteristics of filling materials. In this study, the sedimentation property of iron tailings with a cement-sand ratio of $1: 4$ and mass concentration of $73 \% \sim 82 \%$ was investigated based on rheology measurements. Results showed that shear stress increased as shear rate rose from $0 \mathrm{~s}^{-1}$ to $120 \mathrm{~s}^{-1}$. The shear stress increased as the filling material concentration increased as well. However, when the shear rate was reversed from $120 \mathrm{~s}^{-1}$ to $0 \mathrm{~s}^{-1}$, the shear stress presented an increase-constant-decrease change pattern as the mass concentration increases in the rheological curve. Accordingly, the sedimentation performance of iron tailings filling material was divided into three types: intense sedimentation (the ascending rheological curve) in the mass concentration range of $73 \% \sim 76 \%$, slight sedimentation (the constant rheological curve) in the mass concentration range of $77 \% \sim 79 \%$, and almost no sedimentation (the descending rheological curve) in the mass concentration range of $80 \% \sim 82 \%$. The associated mechanism involving slurry mass concentration-rheological curves-sedimentation performance was illustrated. A correlation between the pipeline rheology and filling material sedimentation performance was established, which provides a practical guide to avoid pipeline blocking while transporting the filling material.
\end{abstract}

\section{Introduction}

The backfill mining method is commonly employed in the mineral resources exploitation for nonferrous and precious metals. Due to the increasing mining depth, more and more iron mines have started to use the backfill mining method for safety causes [1-3]. Comparing with nonferrous metal mine tailings, the iron tailings feature a coarse particle size distribution and a high grade of metal content. This coarse particle size leads to a higher sedimentation property and poorer stability for iron tailings backfill materials [4]. As the coarse particles gradually deposit in the pipeline during the filling process, a pipe-blocking accident could occur, seriously impacting the backfill efficiency and increasing the operation cost $[5,6]$. In addition, a high mass concentration will bring new problems of high pressure and energy consumption. Therefore, a suitable concentration is desired to avoid the particle sedimentation.

At present, many studies focused on the segregation and fluidity property of the filling material $[7,8]$. However, the quantitative characterization of the sedimentation performance for the backfill material is rarely reported. In general, increasing nonsilting velocity of the backfill material during the transportation can avoid the sedimentation of the backfill material [9]. Indeed, nonsilting velocity theory also depends on the concentration of the backfill material. As the concentration of the backfill material increases, its nonsilting velocity is expected to decrease. However, increasing flow rate is not an economical option for the mitigation of pipe wear, since increasing flow rate can speed up the pipe wear 
$[10,11]$. Therefore, a suitable concentration choice is beneficial to not only control the sedimentation of the backfill material but also reduce pipeline wear.

The rheological property is sensitive to the variation of backfill slurry concentration. In addition, rheological property is believed to be a reliable factor for describing the backfill slurry pipeline transportation [12]. Hence, this research aims at investigating the sedimentation property of the backfill material by conducting a series of rheological tests of the iron tailings backfill material with various mass concentrations. Further, a relationship between the rheological property and sedimentation performance in the backfill mining technology was also established.

\section{Materials and Methods}

2.1. Experimental Materials and Proportion. The composition of iron tailings and 32.5 Portland cement used in the experiments is based on the practical backfill situation of iron mines from China. The true density of iron tailings used is $2.83 \mathrm{t} / \mathrm{m}^{3}$, and the cement material is $3 \mathrm{t} / \mathrm{m}^{3}$. The water used to mix the tailings is common tap water. The ratio of cement to tailings in the experiment is $1: 4$. Ten groups of $1000 \mathrm{~g}$ slurry samples ranging from $73 \%$ to $82 \%$ in mass concentration were prepared. Table 1 shows the particle size distribution of the iron tailings, indicating particles finer than $100 \mu \mathrm{m}$ occupy $69 \%$. Still, coarse particles are relatively abundant compared to the nonferrous metal tailings [12, 13].

2.2. Testing Method. A Brookfield R/S + rheometer was used to measure rheological properties of backfill slurry in this experiment [14]. Compared with traditional cylinder rheometers, the rheometer only slightly alters the structure of samples for its special cross rotator design (V60_30_3tol). The cross rotator could avoid the slip effect of cylinder surface and significantly improves accuracy of measurements [12].

The slurry samples were poured into $500 \mathrm{ml}$ beakers and mixed for $5 \mathrm{~min}$ to ensure homogeneity. The rotator was kept $2 \mathrm{~cm}$ away from the bottom of the beaker during the mixing process. In the rheometer setup, rheological parameters were tested through controlling shear rate (CSR). When measuring the thixotropy, the shear history and time scales are crucial [4]. The Bingham model is usually employed for prediction in pipeline transport as relevant shear rate ranges from 10 to $100 \mathrm{~s}^{-1}$. However, it is possible that the corresponding shear rates were quite low (e.g., zero at start-up conditions) [12]. Therefore, shear rates applied in typical rheological experiments of backfill materials were extended from 0 to $120 \mathrm{~s}^{-1}$. At the same time, the shear time is set at $120 \mathrm{~s}$. In this study, improvements on the measurement method (shear rate increased from $0 \mathrm{~s}^{-1}$ to $120 \mathrm{~s}^{-1}$ and then back to $0 \mathrm{~s}^{-1}$, corresponding to constant shear time as $120 \mathrm{~s}$ for both shear rate periods) were made for the emphasis on sedimentation properties at various mass concentrations of the backfilling material. Analysis on evolution law observed from the rheological curve was performed to identify changes of the slurry structure and sedimentation properties of backfill slurry.
Table 1: Particle size distribution of the iron tailings.

\begin{tabular}{lcccccccc}
\hline Screen size $(\mu \mathrm{m})$ & 2000 & 250 & 150 & 100 & 74 & 45 & 38 & 20 \\
\hline $\begin{array}{l}\text { Cumulative percentage } \\
\text { of finer }(\%)\end{array}$ & 100 & 91 & 81 & 69 & 60 & 40 & 32 & 26 \\
\hline
\end{tabular}

2.3. Rheological Theoretical Models. This paper mainly concentrates on the settling properties of tailings suspensions based on rheological theories. Hence, the relationship between settling properties and rheological parameters for coarse tailings was deduced.

The settling phenomenon of tailings particles is closely linked to forces involved in suspensions. The forces received by coarse particles consist of gravity, buoyance, and adhesion between particles. The forces involved in tailings suspensions are illustrated in Figure 1. When suspensions have an excellent nonsettling property, the resultant of forces involved should be zero. When coarse particles float or sink, the adhesive force supplied by the suspension system should be smaller than the resultant of gravity and buoyance.

This paper involves coarse particles in which the density is bigger than suspensions. Therefore, there is a downward direction of resultant of gravity and buoyance. At the same time, the adhesive force is upward. The resultant of forces for coarse particles under the static condition can be expressed as

$$
F_{\mathrm{r}}=G-f_{\mathrm{f}}-f_{\mathrm{a}},
$$

where $F_{\mathrm{r}}$ is the resultant of forces, $G$ is the gravity received by coarse particles, $f_{\mathrm{f}}$ is the buoyance to which the coarse particle is subjected, and $f_{\mathrm{a}}$ is the adhesive force received by coarse particles.

The resultant of forces to which coarse particles are subjected is zero as tailings particles do not settle. The adhesive force is highly related with the tailings suspension system, and the maximum of $f_{\mathrm{a}, \max }$ occurs. When $f_{\mathrm{a} \text {,max }}<G-f_{\mathrm{f}}$, the resultant of forces for coarse particles is not equal to zero, and then the settlement of tailings would happen. If $f_{\mathrm{a} \text {, max }}>G-f_{\mathrm{f}}$, the resultant of forces is upwards and the settlement phenomenon is not easy to occur.

Therefore, only if the adhesive force to which coarse particles are subjected is large enough, the suspension could become an excellent nonsettling fluid:

$$
f_{\mathrm{a}, \max } \geq G-f_{\mathrm{f}}=\left(\rho_{\mathrm{c}}-\rho_{\mathrm{s}}\right) g V,
$$

where $\rho_{\mathrm{c}}$ is the apparent density of coarse particles, $\rho_{\mathrm{s}}$ is the density of the tailings suspension, $g$ is the acceleration of gravity, and $V$ is the volume of coarse particles.

The maximum adhesive force supplied by tailings suspensions is related with the yield stress of suspensions [15]. Previous study reports that $f_{\text {a,max }}$ can be expressed as follows [16]:

$$
f_{\mathrm{a}, \max }=A \tau_{0} .
$$

The yield stress of suspensions is related with conditions of suspensions. In common, the yield stress consists of static yield stress and dynamic yield stress. The static yield stress is the minimum of shear stress below which the movement of 


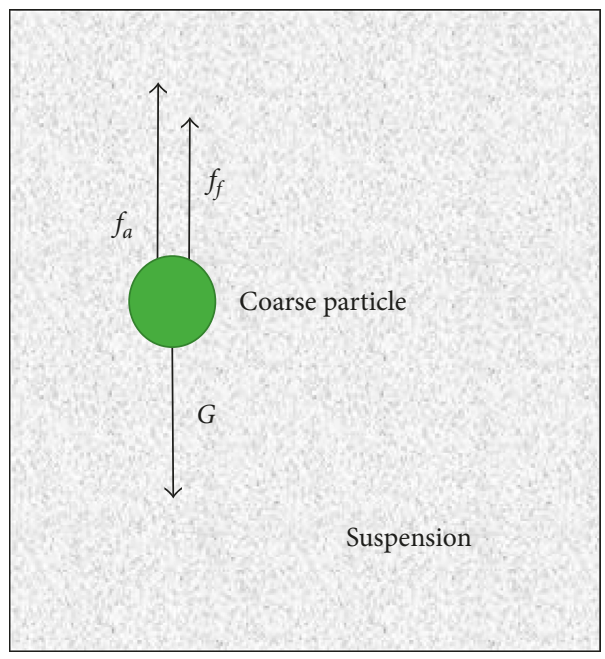

Figure 1: Analysis of forces received by the coarse particle.

suspensions cannot occur. Herein, we measured the static yield stress in experiments and obtained the maximum adhesive force under static conditions:

$$
f_{\mathrm{a}, \max }=C \cdot A \cdot \tau_{\mathrm{s}},
$$

where $\tau_{0}$ is the yield stress of suspensions, $\tau_{\mathrm{s}}$ is the static yield stress of suspensions, $A$ is the sectional area in the direction of movement, and $C$ is the coefficient of the adhesive force, ideally $C$ is 1 as the shape of particles is sphere, while commonly $C$ is about $1.2 \sim 2$ for nonsphere particles [17].

To ensure that the settlement of coarse tailings particles does not occur, the maximum adhesive force supplied by suspensions should exceed the adhesive force to which the coarse particles are subjected. Combining (2) and (4), the conditional formula of nonsettling coarse tailings suspensions can be deduced. In addition, $V=\pi d^{3} / 6$ and $A=\pi d^{2} / 4$, and hence, the expression can be illustrated as

$$
\begin{array}{ll}
\tau_{\mathrm{s}} \geq \frac{2\left(\rho_{\mathrm{c}}-\rho_{\mathrm{s}}\right) g d}{3 C}, & \text { nonsettling } \\
\tau_{\mathrm{s}}<\frac{2\left(\rho_{\mathrm{c}}-\rho_{\mathrm{s}}\right) g d}{3 C}, & \text { settling, }
\end{array}
$$

where $d$ is the diameter of coarse particles, while the equivalent diameter of nonspherical particles is $d_{\mathrm{e}}=(6 \mathrm{~V} / \pi)^{1 / 3}$.

It can be seen that the settling properties of tailings suspensions are related with not only the density and diameter of particles but also the yield stress of suspensions. The coefficient of adhesive force gets improved when the yield stress of suspensions increases. Furthermore, the suspension tends to be nonsettling as the yield stress of suspensions increases.

\section{Results and Discussion}

3.1. Tailings Chemical Composition. The mineralogical analysis on micronized tailings was performed by X-ray

\begin{tabular}{|c|c|}
\hline Chemical composition & Content $(\%)$ \\
\hline $\mathrm{SiO}_{2}$ & 53.20 \\
\hline $\mathrm{Al}_{2} \mathrm{O}_{3}$ & 14.69 \\
\hline $\mathrm{CaO}$ & 5.84 \\
\hline $\mathrm{Fe}_{2} \mathrm{O}_{3}$ & 6.78 \\
\hline $\mathrm{MgO}$ & 3.95 \\
\hline $\mathrm{Na}_{2} \mathrm{O}$ & 3.76 \\
\hline $\mathrm{K}_{2} \mathrm{O}$ & 2.98 \\
\hline $\mathrm{SO}_{3}$ & 1.20 \\
\hline $\mathrm{TiO}_{2}$ & 0.58 \\
\hline $\mathrm{P}_{2} \mathrm{O}_{5}$ & 0.24 \\
\hline Loss-on-ignition (LOI) & 5.39 \\
\hline Total & 98.61 \\
\hline
\end{tabular}
diffraction (XRD), which is given in Table 2. In order to
TABLE 2: Chemical composition of the tailings.

ensure that all particles are finer than $80 \mu \mathrm{m}$, powders of specimens were prepared by grinding. The equipment for $\mathrm{XRD}$ analysis was applied with an incident radiation of $\mathrm{Cu}$ $\mathrm{Ka}$ and an acceleration voltage of $35 \mathrm{kV}$ and $30 \mathrm{~mA}$. Data collection was carried out at angles ranging from $10^{\circ}$ to $80^{\circ}$. The angel size step in data collection is $0.005^{\circ}$. The counting time per step is $0.5 \mathrm{~s}$. The main chemical composition of the tailings sample is $\mathrm{SiO}_{2}$, occupying $53.20 \%$ in mass fraction.

3.2. Evolution of Shear Stress-Shear Rate Curve. To analyze the relationship between shear stress and shear rate, this study selected data from $0 \mathrm{~s}^{-1}$ to $120 \mathrm{~s}^{-1}$ in shear rate. Additionally, the rheological curve from $120 \mathrm{~s}^{-1}$ to $0 \mathrm{~s}^{-1}$ in shear rate was analyzed to identify sedimentation properties of backfill slurry later in Section 3.4. Figure 2 shows the rheological curve from $0 \mathrm{~s}^{-1}$ to $120 \mathrm{~s}^{-1}$ in shear rate at different mass concentrations. As described in Figure 2, at a given mass concentration of backfill slurry, the shear stress keeps almost in line with shear rate and increases with increasing shear rate. When mass concentration of slurry grows, shear stress would increase as well. However, the shear stress increases abruptly in the beginning $5 \mathrm{~s}$ after shear rate starts to change and then drops in a short period until it comes into steady growth after another $5 \mathrm{~s}$. This sudden change becomes more evident as the mass concentration of slurry grows. This is attributed to high resistance for breaking the structure of slurry and overcoming friction of particles when the rotator begins to rotate in slurry of high mass concentration [12].

\subsection{Evolution of Apparent Viscosity-Shear Time Curve.} Figure 3 presents changes of apparent viscosity with shear time at various shear rates between $0 \mathrm{~s}^{-1}$ and $120 \mathrm{~s}^{-1}$. Overall, the apparent viscosity of slurry decreases when shear time increases. This is mainly attributed to destruction of the flocculation network structure formed between tailingscement particles. At the same time, the apparent viscosity of each slurry sample increases with increasing mass concentration. Furthermore, when mass concentration gets higher, the change curve between apparent viscosity and shear time tends to be smoother. It is on account of better homogeneity of slurry and less disturbance for mixing in slurry of high mass concentration. The application background of this study is pipeline transportation 


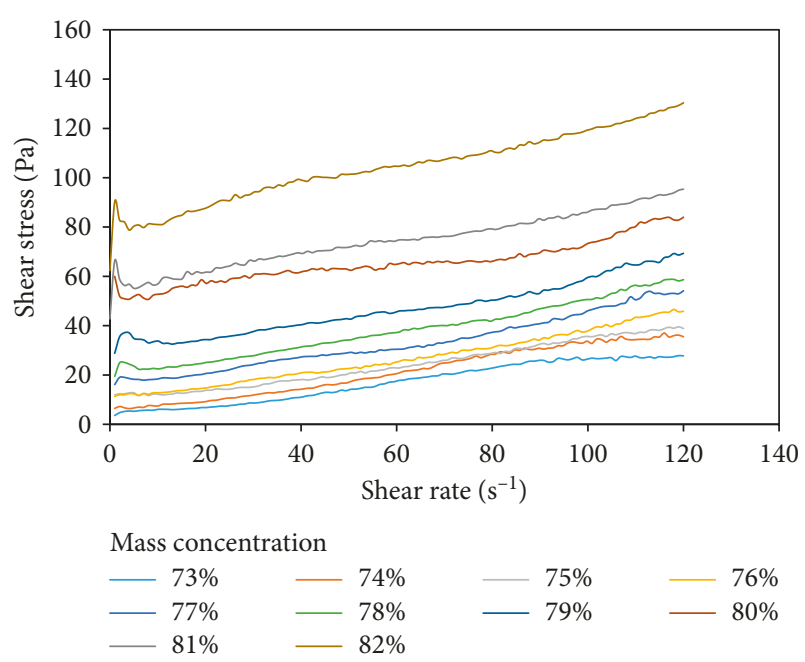

FIGURE 2: Relationship between shear stress and shear rate of different slurry mass concentrations.

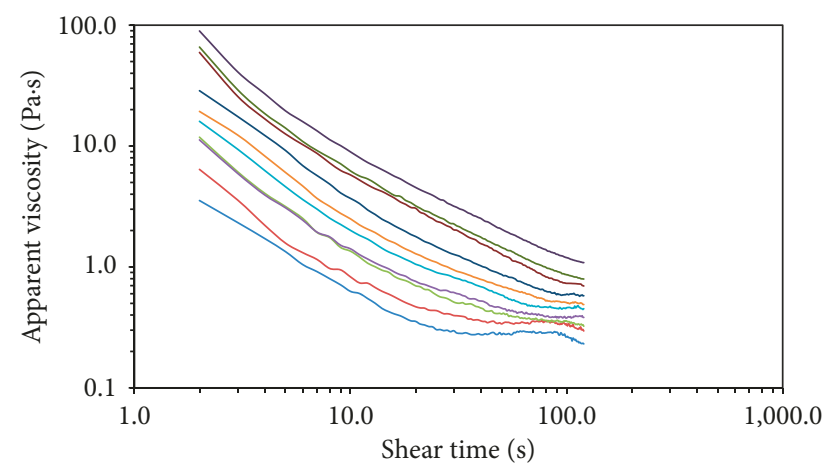

\begin{tabular}{lrrr}
\multicolumn{2}{l}{ Mass concentration } \\
$-73 \%$ & $-76 \%$ & $-79 \%$ & - \\
$-71 \%$ \\
$-74 \%$ & $-77 \%$ & $-80 \%$ & $-82 \%$ \\
$75 \%$ & $78 \%$
\end{tabular}

FIGURE 3: Relationship between apparent viscosity and shear time of different slurry mass concentrations.

technology for metal mines. Indeed, the influence of mineral concentration on the rheological properties of the slurry's viscosity is also time-scale dependent. For example, the effect of concentration on viscosity was performed by Nascimento and Calado [18] on bauxite slurry. The tests were carried out with both cylinder and vane rheometers by applying three steps. Firstly, the shear rate increased from 0 to $200 \mathrm{~s}^{-1}$ in $100 \mathrm{~s}$. Secondly, the shear rate was kept constant at $200 \mathrm{~s}^{-1}$ for $15 \mathrm{~s}$. At last, the shear rate decreased to $0 \mathrm{~s}^{-1}$ in $100 \mathrm{~s}$. The test results show that rheopexy degree increased when the slurry concentration increased for both rotors. An abrupt viscosity drop was observed at the time scale of initial $50 \mathrm{~s}$, since a higher deformation level occurred because of a real transition from a solid to a fluid state. It should be noted that this solid-fluid state transition is similar to the results of this study.

3.4. Sedimentation Property of Backfilling Material. Figure 4 presents the rheological curve with shear rate from $0 \mathrm{~s}^{-1}$ to $120 \mathrm{~s}^{-1}$ for slurry at various mass concentrations. In Figure 4 (a), mass concentration of slurry varies from $73 \%$ to $76 \%$, and shear stress evidently increases when shear rate drops from $120 \mathrm{~s}^{-1}$ to $0 \mathrm{~s}^{-1}$. The shear process is beneficial for quick dewatering in slurry of low mass concentration, and this dewatering leads to a thickening of slurry that results in a growth of shear stress. When the mass concentration of slurry is $73 \%$, practical sedimentation situation of slurry after the shear process of $0 \mathrm{~s}^{-1}$ to $120 \mathrm{~s}^{-1}$ is given in Figure 5 . Obvious bleeding and sedimentation compared with initial period of mixing process can be seen in the figure. Therefore, the shear stress with shear rate changing from $120 \mathrm{~s}^{-1}$ to $0 \mathrm{~s}^{-1}$ is larger than initial shear stress.

When mass concentration of slurry increases from $77 \%$ to $79 \%$ and shear rate decreases from $120 \mathrm{~s}^{-1}$ to $0 \mathrm{~s}^{-1}$, respectively, shear stress has no increase and keeps as almost a flat trend, as shown in Figure 4(b). However, the shear curve with shear rate changing from $120 \mathrm{~s}^{-1}$ to $0 \mathrm{~s}^{-1}$ is higher than that with shear rate changing from $0 \mathrm{~s}^{-1}$ to $120 \mathrm{~s}^{-1}$, indicating shear stress of slurry in return process of shear rate is still bigger than initial shear stress. When mass concentration of slurry reaches between $77 \%$ and $79 \%$, especially after shear rate increasing from $0 \mathrm{~s}^{-1}$ to $120 \mathrm{~s}^{-1}$, the bleeding phenomenon is relatively less obvious than at mass concentration of 73\% 76\% (shown in Figure 5). Although the increase of the mass concentration leads to a decrease of slurry's sedimentation, the sedimentation phenomenon of slurry also exists.

In Figure 4(c), the mass concentration of slurry further reaches $80 \% \sim 82 \%$, and shear stress decreases with shear rate decreasing from $120 \mathrm{~s}^{-1}$ to $0 \mathrm{~s}^{-1}$, different evidently from those in Figure 4(a) and 4(b). This indicates flocculation structure of slurry breaks and no evident sedimentation phenomenon occurs when mass concentration of slurry exceeds $80 \%$, after shear rate increasing from $0 \mathrm{~s}^{-1}$ to $120 \mathrm{~s}^{-1}$. The bleeding phenomenon for slurry of $82 \%$ in mass concentration, after shear rate increasing from $0 \mathrm{~s}^{-1}$ to $120 \mathrm{~s}^{-1}$, confirms this behavior that shown in Figure 5.

3.5. Classification Method of Sedimentation for Backfill Material. Based on the analysis mentioned above, rheological curves (shear rate changes from $0 \mathrm{~s}^{-1}$ to $120 \mathrm{~s}^{-1}$ and then drops to $0 \mathrm{~s}^{-1}$ ) could be divided into three types including intense sedimentation $(73 \% \sim 76 \%$ in mass concentration), slight sedimentation (77\% 79\%), and almost no sedimentation $(80 \% \sim 82 \%)$, corresponding to three curves in Figure 6. It should be noted that this classification and shape of the rheological curves only apply to the time scales of this study and this tailings slurry, and further work will be performed to perfect and generalize this classification.

(1) Intense sedimentation (rheological curve rises). The feature of the rheological curve is represented as an increase of shear stress both when shear rate grows from $0 \mathrm{~s}^{-1}$ to $120 \mathrm{~s}^{-1}$ and when it drops from $120 \mathrm{~s}^{-1}$ to $0 \mathrm{~s}^{-1}$, as shown in Figure 6(a). The shear behavior causes higher mass concentration of slurry, which is detrimental to stop and restart pumping. 

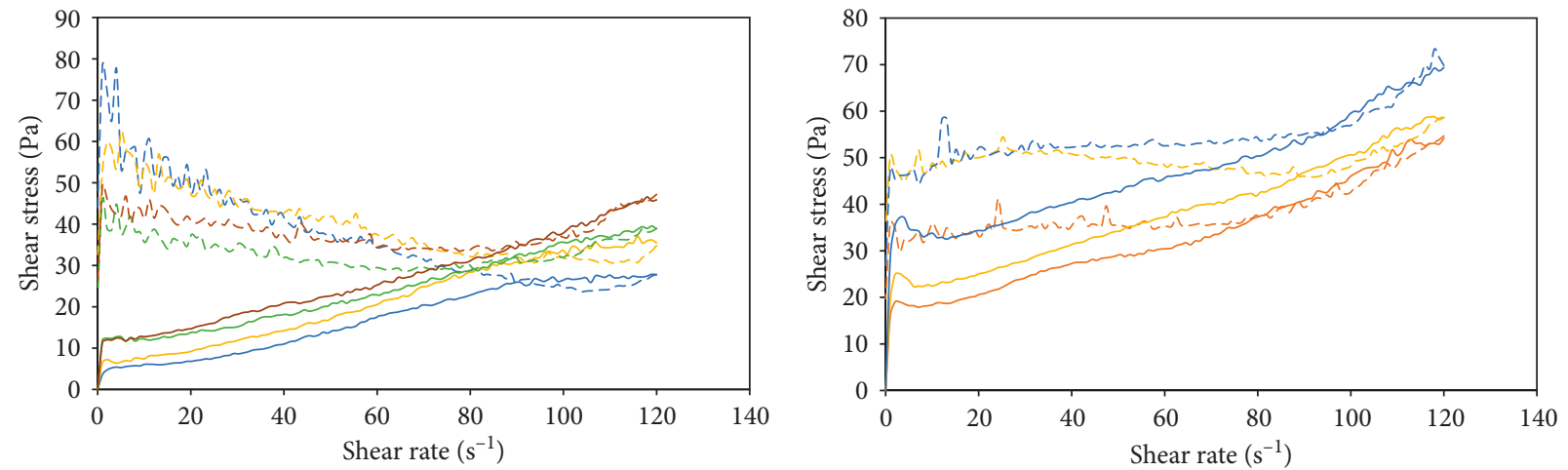

Mass concentration

$\begin{array}{rlr}-73 \%-1 & -76 \%-1 & --75 \%-2 \\ -74 \%-1 & --73 \%-2 & ---76 \%-2 \\ -75 \%-1 & --74 \%-2 & \end{array}$

(a)

Mass concentration

$\begin{array}{rr}-77 \%-1 & --77 \%-2 \\ -78 \%-1 & --78 \%-2 \\ -79 \%-1 & ---79 \%-2\end{array}$

(b)

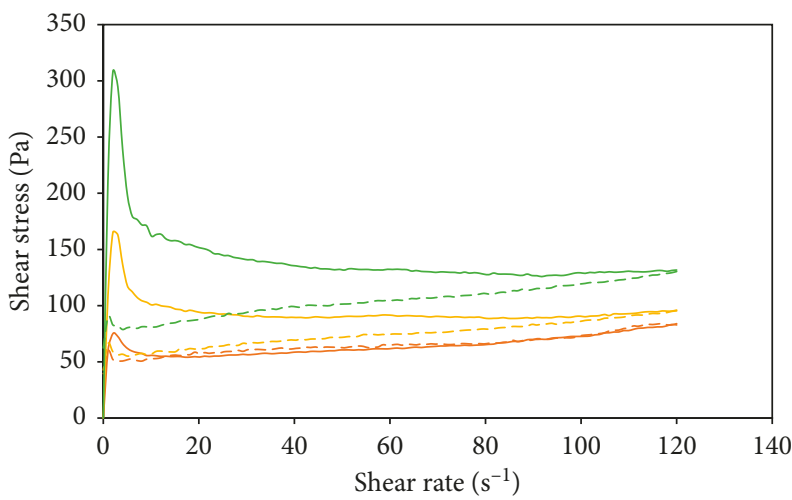

Mass concentration

$\begin{aligned}-80 \%-1 & --80 \%-2 \\ -81 \%-1 & --81 \%-2 \\ -82 \%-1 & ---82 \%-2\end{aligned}$

(c)

FiguRE 4: Shear stress-shear rate curve of various slurry concentrations (\%-1 solid lines represent $0 \sim 120 \mathrm{~s}^{-1}$; \%-2 dashed lines represent 120 $0 \mathrm{~s}^{-1}$ ): (a) 73\% 76\% mass concentration; (b) 77\% 79\% mass concentration; (c) $80 \% \sim 82 \%$ mass concentration.
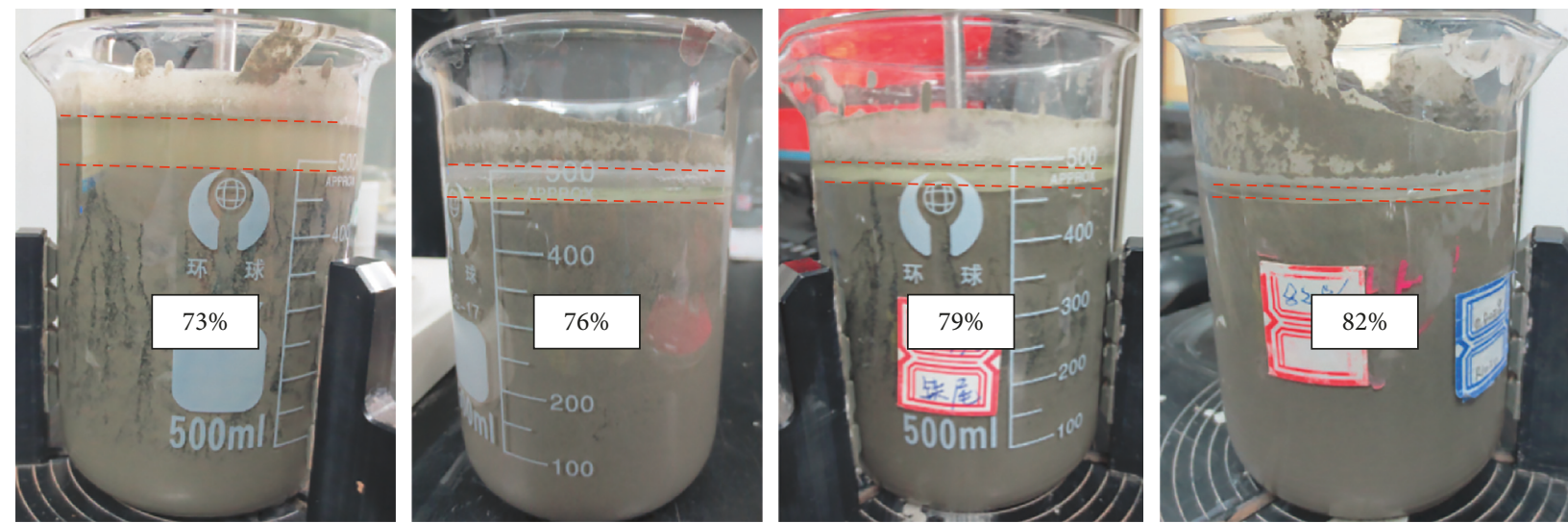

FIGURE 5: Practical bleeding situation of slurry (with different mass concentrations of $73 \%, 76 \%, 79 \%$, and $82 \%$ ) after the shear rate of $0 \mathrm{~s}^{-1} \sim 120 \mathrm{~s}^{-1}$. 


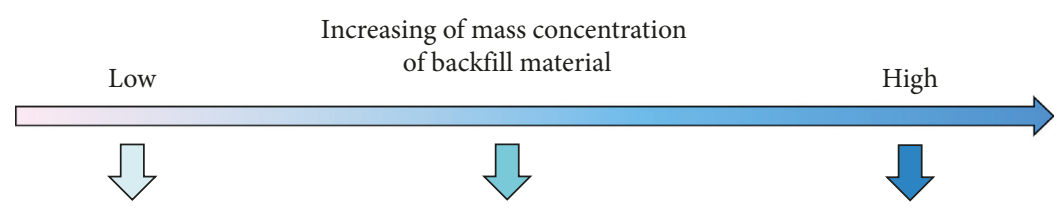

(a) Rheological curve ascend

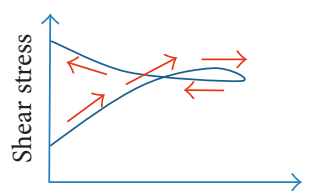

Shear rate

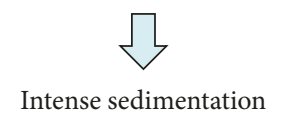

(b) Rheological curve ascend

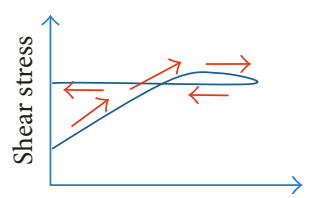

Shear rate

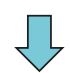

Slight sedimentation (c) Rheological curve descend

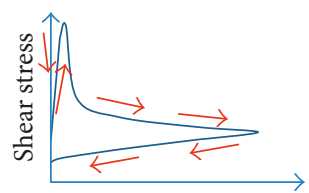

Shear rate

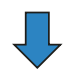

Almost no sedimentation

Suitable for the tailings that contains more coarse particles

FIGURE 6: Slurry mass concentration-rheological curve figure-sedimentation performance-associated mechanism.

(2) Slight sedimentation (rheological curve keeps almost flat). The feature of the rheological curve is represented as an increase of shear stress with shear rate growing from $0 \mathrm{~s}^{-1}$ to $120 \mathrm{~s}^{-1}$ and a placid shear stress with shear dropping from $120 \mathrm{~s}^{-1}$ to $0 \mathrm{~s}^{-1}$, respectively, as shown in Figure 6(b). The shear behavior causes a small amount of sedimentation and bigger shear stress than initial shear stress.

(3) Almost no sedimentation (rheological curve drops). The feature of the rheological curve is represented as a decline of shear stress with shear rate increasing from $0 \mathrm{~s}^{-1}$ to $120 \mathrm{~s}^{-1}$ and also a decline of shear rate drop from $120 \mathrm{~s}^{-1}$ to $0 \mathrm{~s}^{-1}$, respectively, as shown in Figure 6(c). The shear behavior causes destruction of the flocculation structure in slurry but almost no sedimentation occurs, indicating the slurry as homogeneous flow, which is beneficial to pipeline transport, as well as to stop and restart pumping. At the same time, this means higher transport resistance and higher energy consumption, available for deep mine backfill demanding high resistance and low pressure.

It is worth mentioning that the mass concentration of slurry, corresponding to the rise of the rheological curve, is widely applied in industrial backfill activities nowadays. Therefore, when coarse particles are relatively rich in backfill slurry, the rise of the rheological curve should be high. If this phenomenon becomes evident, sedimentation of backfill slurry in pipeline transport tends to be serious, potentially influencing transport flow and being easy to cause a pipe blockage accident. At the same time, the backfill material transported into stopes has obvious phenomenon of bleeding, attributing to loss of cement, which causes high cement consumption and inhomogeneous strength distribution in the backfill body. Though this study is carried out with iron tailings, it is also meaningful for other backfill slurries containing similar or some more coarse particles.
3.6. Sedimentation Property of Backfilling Material from the Viewpoint of Yield Stress. It is necessary to further discuss sedimentation properties of backfill slurry based on shear stress, intuitively reflecting the relationship between rheological parameters and sedimentation properties. This study performs the Bingham rheological model analysis on the curve between shear stress and shear rate, which is a simple and common method for backfill slurry yield stress regression [12]. Table 3 shows the results clarifying shear stress and plastic viscosity at various mass concentrations of slurry.

The multiple correlation coefficient of Bingham regression analysis is close to 1.0 (Table 3 ) for slurry at various mass concentrations, showing the Bingham model is suitable to the rheological curve of iron tailings slurry. The relationship between yield stress and mass concentration is plotted in Figure 7. From Figure 7, we can see that the shear stress gradually increases with the increase of mass concentration of slurry, which is characterized by the classical growth curve of shear stress, widely identified by other studies [12, 19-21]. Based on different sedimentation sections classified by mass concentration of slurry, combining with changes of yield stress shown in Figure 7, it can be seen that evident sedimentation phenomenon happens at a low yield stress and keeps in line with mass concentration of slurry. The slight sedimentation occurs before yield stress changes abruptly. Almost no sedimentation happens after the yield stress changes abruptly. In fact, these sections classified by yield stress are, respectively, corresponding to low-concentration backfill, high-concentration backfill, and paste backfill, which has been recognized widely in previous studies [22].

The final purpose of this study was to establish the relationship between the settling ratio and rheological parameter. The settling ratio is defined as the settling height to the total height of slurry. The simultaneous evolution of settling ratio and yield stress is given in Figure 8. From Figure 8 , it can be seen that settling ratio of backfilling slurry 
TABLE 3: Bingham rheological model regression for each mass concentration.

\begin{tabular}{lcccc}
\hline Mass concentration (\%) & Regression equation & Yield stress (Pa) & Plastic viscosity $(\mathrm{Pa} \cdot \mathrm{s})$ & Multiple correlation coefficient \\
\hline 73 & $\tau=2.9852+0.2309 \gamma$ & 2.9852 & 0.2309 & 0.9759 \\
74 & $\tau=4.0780+0.2848 \gamma$ & 4.0780 & 0.2848 & 0.9876 \\
75 & $\tau=8.6126+0.2558 \gamma$ & 8.6126 & 0.2558 & 0.9873 \\
76 & $\tau=8.9258+0.2933 \gamma$ & 8.9258 & 0.2933 & 0.9877 \\
77 & $\tau=13.703+0.3159 \gamma$ & 13.703 & 0.3159 & 0.974 \\
78 & $\tau=18.281+0.3246 \gamma$ & 18.281 & 0.3246 & 0.9909 \\
79 & $\tau=27.470+0.3168 \gamma$ & 27.470 & 0.3168 & 0.9718 \\
80 & $\tau=51.305+0.2329 \gamma$ & 51.305 & 0.2329 & 0.9217 \\
81 & $\tau=55.709+0.3105 \gamma$ & 55.709 & 0.3105 & 0.9892 \\
82 & $\tau=80.482+0.3947 \gamma$ & 80.482 & 0.3947 & 0.9865 \\
\hline
\end{tabular}

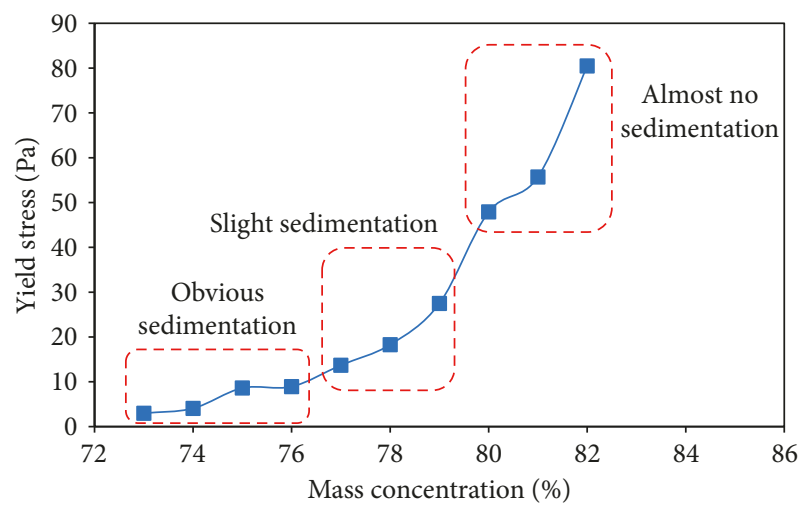

FIGURE 7: Evolution of yield stress as the slurry concentration increases.

decreased as yield stress increased. This is in agreement with (6) that is deduced in this study. At the mass concentration of $73 \%$, the settling ratio is $22.2 \%$ after a 120 s mixing of a rheometer (shear rate rising from $1 \sim 120 \mathrm{~s}^{-1}$ ). When the mass concentration increased to $76 \%$, the settling ratio decreased to $16.7 \%$ at the same mixing condition. As the mass concentration increased to $79 \%$ and $82 \%$, the settling ratio is smaller than $10 \%$ (i.e., $8.6 \%$ and $2.9 \%$ for settling ratio, resp.).

The relationship between settling ratio and yield stress (6) is illustrated in Figure 9.

$$
y=-5.993 \ln (x)+29.057
$$

where $y$ is the settling ratio (\%) and $x$ is the yield stress $(\mathrm{Pa})$. The multiple correlation coefficient of this function is 0.9952 , which indicates that the logarithmic function is suitable to describe the relationship between the settling ratio and yield stress. When the yield stress goes to $1 \mathrm{~Pa}$, the settling ratio goes to $29.1 \%$. As the yield stress goes to infinity, the settling ratio goes to negative infinity, invalidating the model for large yield stress. However, the physical meaning of this regression function is unreliable as the yield stress goes to infinity.

Based upon tailings characteristics and yield stress, the particle size at which the tailings settle was computed using (6) (the value of $C$ is 1.6 by the average of 1.2 and 2 from (5)), as shown in Figure 10. From this figure, it can be observed that the settling diameter increased as the mass concentration rises $(0.3051$ to $10.9796 \mathrm{~mm}$ for the mass concentration from $73 \%$ to $82 \%$ ). This variation is in agreement

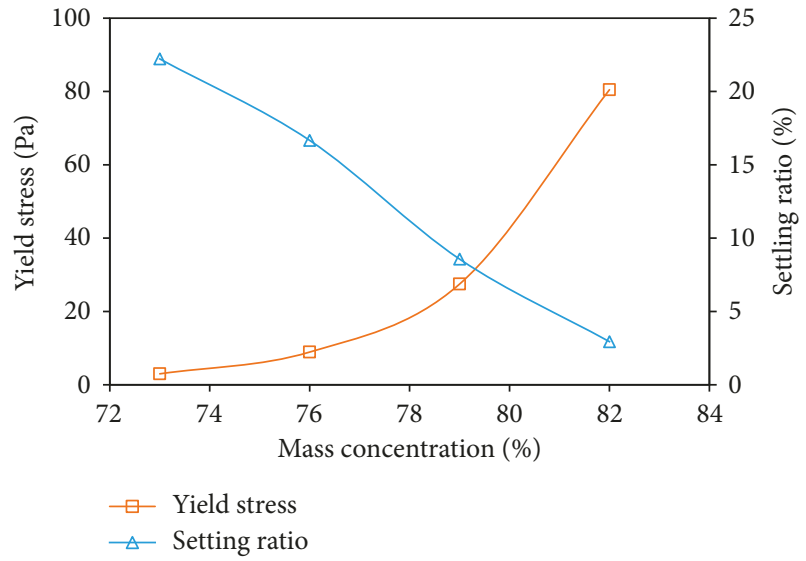

FIGURE 8: Simultaneous evolution of settling ratio and yield stress at various mass concentrations.

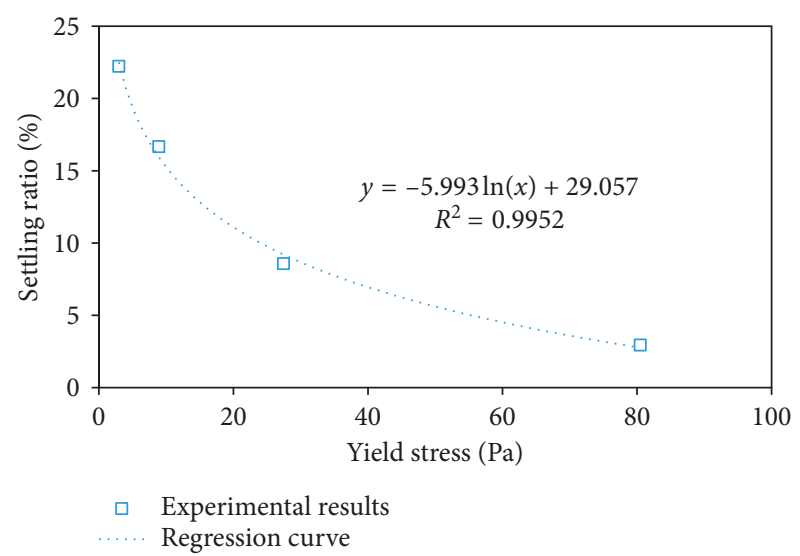

FIGURE 9: Settling ratio versus yield stress of experimental and regression results.

with the associated mechanism in Figure 6. According to Table 1, the maximum diameter of tailings is smaller than $2.00 \mathrm{~mm}$, and particles finer than $0.25 \mathrm{~mm}$ accounts for $91 \%$ of the whole grains. In this case, if the mass concentration is $79 \%$, there should be no sedimentation. However, it still has a settling ratio of $8.57 \%$, which can be attributed to two aspects: (1) the mixing of the rheometer enhanced and speeded up the settling process of tailings and (2) the parameter $C$ in (6) is difficult to be quantified for nonspherical 


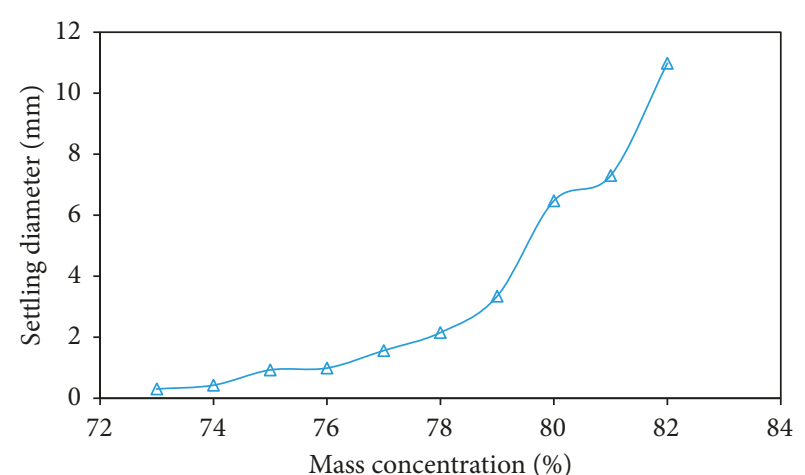

Figure 10: Calculation results of settling diameter at various mass concentrations.

tailings particles, leading to an inaccuracy of settling diameter.

It is necessary to classify that this study investigates sedimentation properties of backfill slurry based on rheology using iron tailings from a specific mine as a sample. It establishes mutual reaction between the rheological curve and shear stress and validates a quantitative evaluation method of sedimentation properties of iron tailings with a series of experiments. More studies in the future will focus on tailings in a wider range containing fine nonferrous tailings, gravels, slag, and other coarse aggregates to modify rheological curves and parameters at various sedimentation properties, optimizing the quantitative evaluation method of sedimentation based on the rheological test. Also, more iron tailings should be analyzed to compare with the results of this study.

\section{Conclusions}

This study attempted to advance our understanding on the sedimentation property of backfill slurry from the viewpoint of rheological characteristics (e.g., evolution of the rheological curve and variation of yield stress). The main conclusions derived from this study are summarized as follows:

(1) A series of the rheological test were performed on iron tailings at various mass concentrations. The shear rate used in this research increases from $0 \mathrm{~s}^{-1}$ to $120 \mathrm{~s}^{-1}$ and then drops from $120 \mathrm{~s}^{-1}$ to $0 \mathrm{~s}^{-1}$, with a total shear time of $240 \mathrm{~s}$. The results indicate shear stress increases with increasing shear rate and mass concentration of slurry. When shear rate drops from $120 \mathrm{~s}^{-1}$ to $0 \mathrm{~s}^{-1}$, shear stress behaves an increasingsteady-decreasing trend with the increase of mass concentration of slurry.

(2) A method for the sedimentation properties classification of backfill slurry was presented on the basis of rheological characteristics. The sedimentation of tailings backfill slurry was divided into three types due to the rheological curve trend as shear rate drops from $120 \mathrm{~s}^{-1}$ to $0 \mathrm{~s}^{-1}$ : (i) intense sedimentation featured with an ascend rheological curve (mass concentration of $73 \% \sim 76 \%$ ), (ii) slight sedimentation featured with a steady rheological curve (mass concentration of $77 \% \sim 79 \%$ ), and (iii) almost no sedimentation with a descend rheological curve (mass concentration of $80 \% \sim 82 \%$ ).

(3) A mechanism map was plotted that describes reaction among mass concentration of slurry, rheological curve, and sedimentation properties. This study proposes that existence of pipe-wall shear behavior in slurry at various mass concentrations causes differences in rheological parameters of slurry. It is available to avoid sedimentation and plugging during pipeline transport through establishment of reaction between rheology in pipeline transport and sedimentation properties of backfill slurry.

\section{Data Availability}

Analyzed and generated datasets underlying the findings of the current study are available from the corresponding author (Yong Wang) on request.

\section{Conflicts of Interest}

The authors declare that there are no conflicts of interest regarding the publication of this paper.

\section{Acknowledgments}

This research was funded by the State Key Research Development Program of China (no. 2017YFC0602903), Research Fund of State Key Laboratory of Coal Resources and Safe Mining, CUMT (no. SKLCRSM18KF006), Fundamental Research Funds for the Central Universities (no. FRF-TP-17-024A1), and China Postdoctoral Science Foundation (no. 2017M620622).

\section{References}

[1] A. Wu and H. Wang, "Paste backfill theory and technology of metal mine," Science Press, 2015.

[2] A. Wu, Y. Wang, and H. Wang, "Status and prospects of the paste backfill technology," Metal Mine, vol. 481, pp. 1-9, 2016.

[3] J. Guo, M. Liu, and B. Zhang, "Study on the deposition mechanism of two-phase flow pipeline in deep filling system," Gold Science and Technology, vol. 24, pp. 86-93, 2016.

[4] H. Usui, Y. Sano, M. Sawada, and T. Hongoh, "Thixotropy of highly loaded coal-water slurries," Journal of Chemical Engineering of Japan, vol. 17, no. 6, pp. 583-588, 1985.

[5] Z. Yang, Q. Gao, D. Chen, and S. Wu, "Backfilled starting modes and pipeline resistance of mixed slurry prepared with waste rocks and tailings," Journal of Wuhan Institute of Technology, vol. 38, pp. 369-375, 2016.

[6] Y. Wang, A. Wu, H. Wang, S. Yin, H. Liu, and C. Kang, "A method to determine deep cone thickener volume and its application," Journal of China University of Mining and Technology, vol. 42, pp. 45-49, 2013.

[7] H. Wang, Y. Wang, and A. Wu, "Research of paste new definition from the viewpoint of saturation ratio and bleeding rate," Journal of Wuhan University of Technology, vol. 33, pp. 85-89, 2011. 
[8] S. Liu, H. Wang, A. Wu, Y. Wang, T. Li, and H. Wang, "Experimental research on paste slump by tiny cylindrical tube," Gold, vol. 33, pp. 21-25, 2012.

[9] D. Gan, F. Gao, C. Chen, H. Lu, and Y. Zhang, "Study on critical conveying velocity of full-tailings filling slurry of high concentration," Metal Mine, vol. 473, pp. 22-26, 2015.

[10] Q. Zhang, J. Zheng, X. Wang, and X. Wang, "A study of the abrasion form and mechanism of backfilling pipelines," Metal Mine, vol. 395, pp. 115-118, 2009.

[11] Y. Wang, A. Wu, H. Wang, X. Yang, F. Zhou, and B. Zhou, "Further development of paste definition from the viewpoint of yield stress," Journal of University of Science and Technology Beijing, vol. 36, no. 7, pp. 855-860, 2014.

[12] A. Wu, Y. Wang, and H. Wang, "Estimation model for yield stress of fresh uncemented thickened tailings: coupled effects of true solid density, bulk density, and solid concentration," International Journal of Mineral Processing, vol. 143, pp. 117-124, 2015.

[13] A. Wu, Y. Wang, H. Wang, S. Yin, and X. Miao, "Coupled effects of cement type and water quality on the properties of cemented paste backfill," International Journal of Mineral Processing, vol. 143, pp. 65-71, 2015.

[14] Y. Wang, A. Wu, Z. Ruan, H. Wang, Y. Wang, and F. Jin, "Temperature effects on rheological properties of fresh thickened copper tailings that contain cement," Journal of Chemistry, vol. 2018, Article ID 5082636, 8 pages, 2018, In press.

[15] L. Jossic and A. Magnin, "Drag and stability of objects in a yield stress fluid," AIChE Journal, vol. 47, no. 12, pp. 2666-2672, 2001.

[16] A. W. Saak, H. M. Jennings, and S. P. Shah, "New methodology for designing self-compacting concrete," ACI Materials Journal, vol. 98, no. 6, pp. 429-439, 2001.

[17] N. Peng, "Study on the segregation resistance mechanism of coarse aggregate filling slurry and its application," Master thesis, University of Science and Technology Beijing, Beijing, China, 2014.

[18] C. R. Nascimento and V. Calado, "The concentration effect on the rheological behavior of bauxite slurry," in Proceedings of the XVth International Congress on Rheology: The Society of Rheology 80th Annual Meeting, Monterey, California, USA, August 2008.

[19] B. Alejo and A. Barrientos, "Model for yield stress of quartz pulps and copper tailings," International Journal of Mineral Processing, vol. 93, no. 3-4, pp. 213-219, 2009.

[20] L. Heymann, S. Peukert, and N. Aksel, "On the solid-liquid transition of concentrated suspensions in transient shear flow," Rheologica Acta, vol. 41, no. 4, pp. 307-315, 2002.

[21] E. J. Windhab, "Fluid immobilization-a structure-related key mechanism for the viscous flow behavior of concentrated suspension systems," Applied Rheology, vol. 10, pp. 134-144, 2000.

[22] R. Jewell and A. Fourie, Paste and Thickened Tailings-A Guide, Australian Centre for Geomechanics, Crawley, UK, 3rd edition, 2015. 

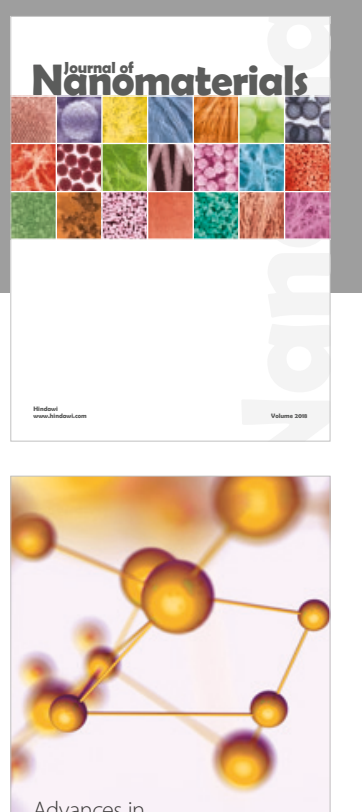

Physical Chemistry
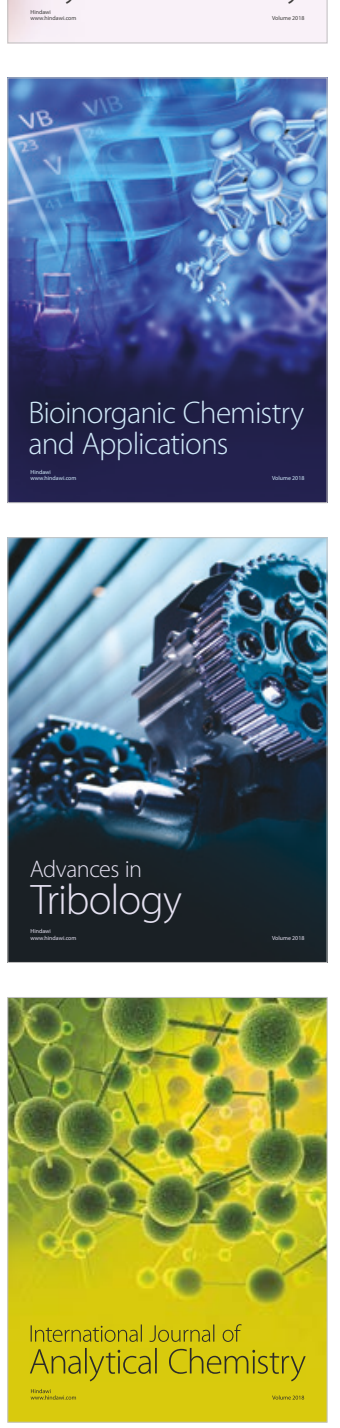

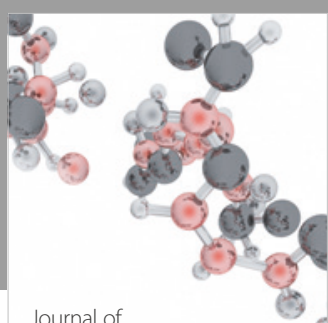

Analytical Methods

in Chemistry

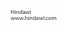

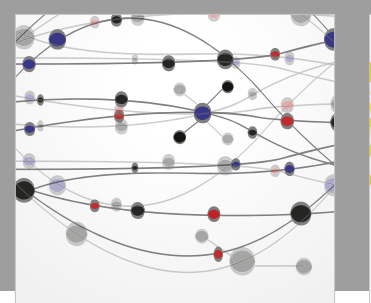

The Scientific World Journal

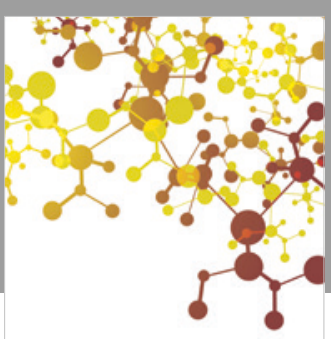

Journal of

Applied Chemistry
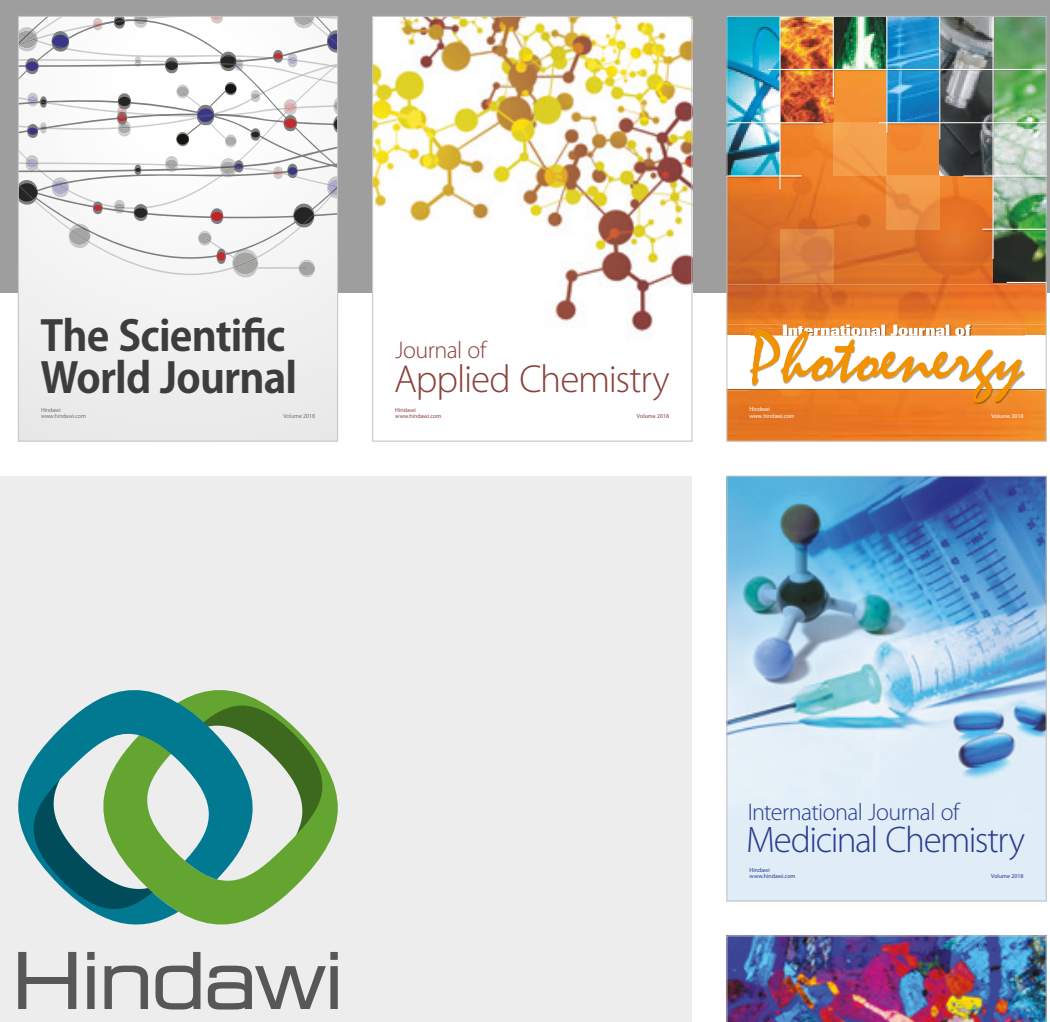

Submit your manuscripts at

www.hindawi.com
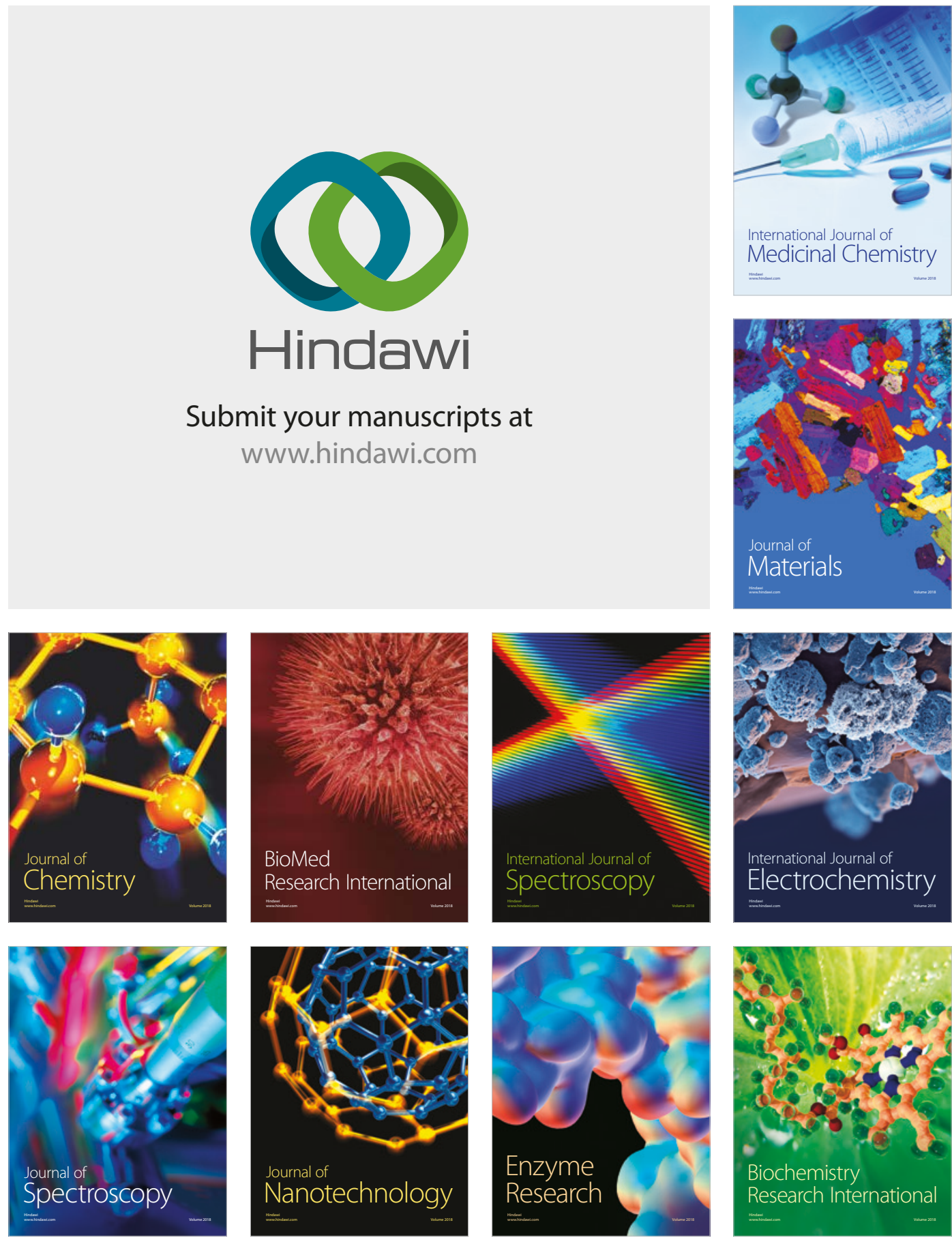
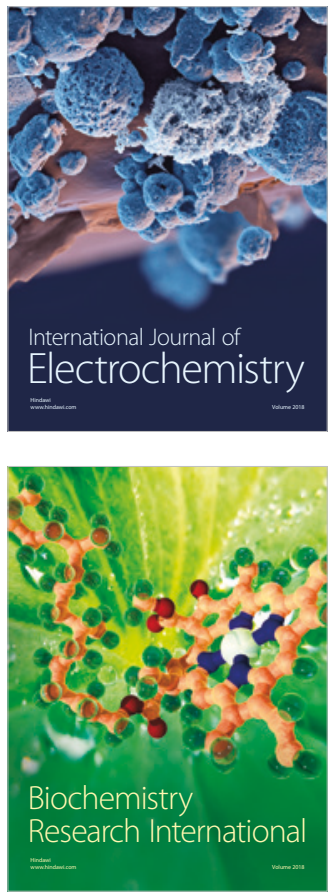